\title{
Mapping perceptions about the influence of critical success factors in BPM initiatives
}

\author{
Tatiane Ribeiro Paixão \\ Helder Gomes Costa \\ Valdecy Pereira \\ Taís Fernandes Costa
}

\begin{abstract}
This article reports a research that has colletected and analyzed perceptions about the influence of CSF in Business Processes (BPM) initiatives. A systematic literature review was performed in papers published in indexed journals. In a second step, a survey was applied to a short sample composed by experts in BPM, with a single question: what area the CSF that most influence in the implementation of process management? After it, a full questionnaire was build and applied to an extended sample composed by Brazilian BPM experts. As a result, the top 10 CSF perceived as most critical to the success in BPM initiatives were identified. The main contributions of this paper are the original way the CSF were elicited and how their importance was found out, both in a systematized and robust way that can be followed by other researches and practioneers.
\end{abstract}

Keywords- Business Process Management, BPM, Critical Factors, CFS, survey

\section{Introduction}

The adoption of BPM is a trend, once it provides improvement in process and organizational results. In the other hand, there is an increase of failures in the process of implementing BPM: as shown in Trkman (2010), about 60\% and $80 \%$ of BPM initiatives have failed. According to Bandara; Gable; Rosemann (2005) to reduce such failures it is necessary to identify and evaluate the critical success factors (CSF) that influence the BPM implementations.

Tatiane Ribeiro Paixão

Mestrado em Sistemas de Gestão / Universidade federal Fluminense Brazil

Helder Gomes Costa

Departamento de Engenharia de Produção / Universidade Federal Fluminense Brazil

\section{Valdecy Pererira}

Departamento de Engenharia de Produção / Universidade Federal Fluminense Brazil

Tais Fernances Costa

ESDI/Universidade do Estado do Rio de Janeiro

Brazil
This article describes a research carried out for finding the CSF thatmost influence the success of BPM initiatives;.

\section{Materials, Methods and Results}

Fig. 1 shows the steps performed in the researvh in order to achieve our objective o four research.

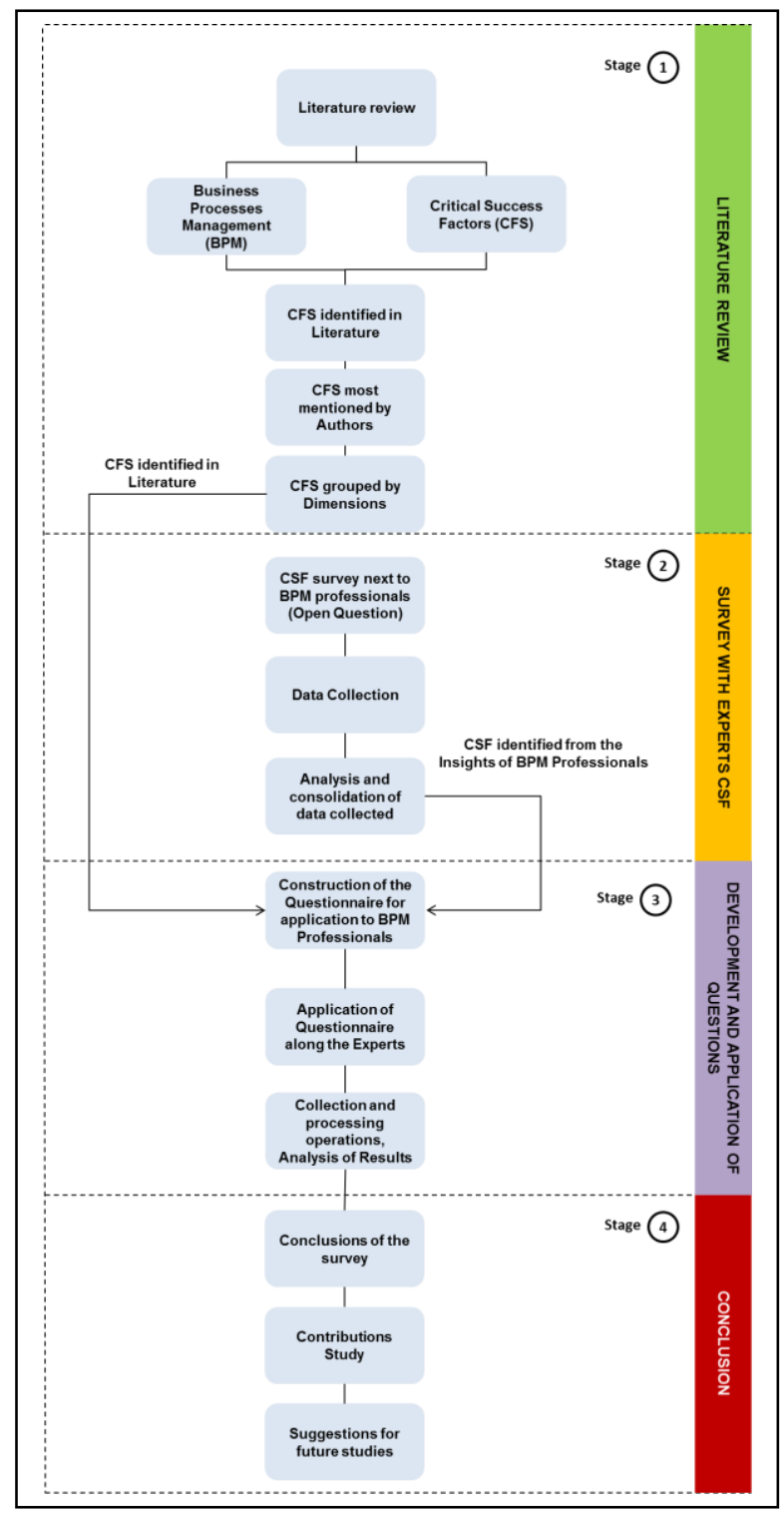

Figure 1. Graphical abstract of the methodology steps 


\section{A. Literature Review}

A set of 23 articles published in journals indexed in SCOPUS or in ISI Web of Science were analyzed looking for critical factors that should influence the implementation of BPM initiatives. The process of searching, selecting and analyzing the references was inspired in Pereira, Costa (2016), Mexas et al. (2012), Da Rocha et al. (2016) and De Freitas, Costa (2016) and has resulted in the selection of the following articles for the literature review: Al-Mudimigh (2007); Alibabaei et al., (2010); Bai; Sarkis (2013); Bandara; Gable; Rosemann (2005); Buh; Kovačič; Štemberger (2015); ABPMP(2013); Ceribeli; De Pádua; Merlo (2013); Da Silva; Damian; De Pádua (2012); De Waal; Batenburg (2012); Goeke; Antonucci (2013); Helfert (2009); Hung (2006); Mutschler; Reichert; Bumiller (2008); Niehaves, Plattfaut, Becker (2013); Ravesteyn; Batenburg (2010); Reijers (2006); Schmiedel; Vom Brocke; Recker (2013); Škrinjar, Trkman (2013); Sentanin; Santos; Jabbour (2008); Štemberger; BosiljVukšić; Jaklič (2009); Tuček; Hájková, Tučková (2013);Vom Brocke; Sinnl (2011); Vom Brocke; Zelt; Schmiedel (2015).

As a result, 52 factors were addressed as critical ones to the success of BPM initiatives. Notice that some terms were standardized according to the similarity, e.g., Schmiedel; Vom Brocke; Recker (2013) the term "Customer orientation", while the Guide ABPMP (2013) mentions the term "Customer Focus". The CSF that is most frequent in the set of paper is "Support and commitment of the High Administration", hat has appeared in 14 of the 23 papers analyzed.

\section{B. Survey with Experts in Business Process Management}

A simplified questionnaire with the alone question: "Based on its experience in process management, what are the factors (variables / conditions) that influence the success of management initiatives for processes, ie, those factors that are considered in their perception as critical to the success of this approach?", was applied to a sample composed by BPM experts with CBPP Certification.

The questionnaire was sent by email to 22 experts that have ate least six (6) years of experience in project management initiatives. Among these experts, 17 answered the questionnaire, and analysing their answers, a set of $37 \mathrm{CSF}$ were identified: The most cited CSF for BPM initiatives was "support and commitment of senior management", which highlights the importance of effective support by the leaders of the organization.

Another aspect highlighted in the survey: eight CSF that have not appeared in the literature review, namely: sustainable performance of processes, ie, maintenance and continuity of process management in the organization; Perception of the value and benefits of management by business processes; Empowerment in the execution of business processes; Periodic audit of business processes; Reduced scope of BPM project; Reward system aligned to business processes; Culture for innovation; Adoption of thematic forums for reflection and discussion about BPM.

\section{Questionnaire and Data Collection}

Sixteen (16) CSF were selected to be included in the questionnaire to be applied to a large sample os experts in BPM. The selection has taken into account: the most cited in the literature review and the most evidenced by the experts surveued in previous step (step B); The CSF were grouped into four dimensions, as presented in the study of Reijers *(2006): Management, Process, Technology and Human.

The data collection was carried out by sending an online Survey Monkey form, with 16 objective questions, to a sample composed by experts that have CBPP certification (Certified Business Process Professional). These experts were early invited to answer the research throughout the LinkedIn network. From 472 professionals contacted, 295 accepted the invitation to answer the research. Finally, a total of 156 professionals answered to the survey, however, there were a total of 136 valid questionnaires effectively. Table 4 shows the scale adopted in the form applied in data collection. This scale is based in Nepomuceno and Costa (2015).

\section{Results}

Table II shows the ranking of the CSF, taking into account their positive influence on BPM initiatives,. I other word, the ranking process has taken into account the sum of the answers "positive influence - very high (VH)" and "high positive influence (VP)" responses. Another point observed refers to the level of positive influence on the rating scale which corresponds to an average of $98.44 \%$ of the answers of the experts, the remaining percentage corresponds to the levels of review "No Influence" (1.19\%); "Negative Influence" (0.28\%) and "does not apply or not answer" $(0.09 \%)$.

It was observed that 110 experts (80.88\% of the sample) indicated the "support and commitment of senior management" as a CSF with a very high level of positive influence on the success of BPM initiatives, The factor "single information technology tool for process modeling" was cited by 14 experts as one does not influencing the success of BPM initiatives, ie $10.30 \%$ of the sample.

Table II shows that the critical success factors related to dimension "technology" did not appear in the first 10 ranking positions. In addition, the CSF 4:15 are tied with a rating of $86.03 \%$, and the CSF 6:13 to $78.68 \%$.

TABLE I. Scale of for evaluation the impact/inflluence of the CSF on the implementationof BPM.

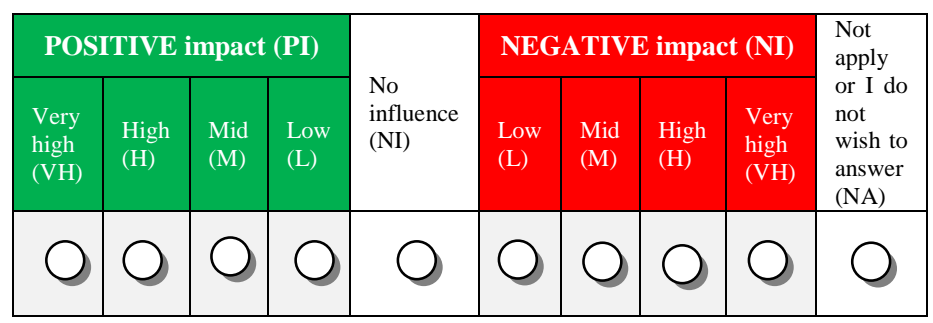


Proc. of the Sixth International Conference on Advances in Social Science, Management and Human Behaviour - SMHB 2017. Copyright ( $\odot$ Institute of Research Engineers and Doctors. All rights reserved.

ISBN: 978-1-63248-141-2 doi: 10.15224/ 978-1-63248-141-2-50

TABLE II. - Ranking of CSF that hasve positive iinfluence/impact on BPM initiatives

\begin{tabular}{|c|c|c|c|}
\hline Dimension & Critical Success Factor & $\begin{array}{c}\% \text { of } \\
\text { answer } \\
\text { (PI-VH and } \\
\text { PI-H) }\end{array}$ & $\begin{array}{l}\text { Ranking } \\
\text { Position }\end{array}$ \\
\hline Management & $\begin{array}{l}\text { Support and commitment of } \\
\text { senior management (CSF- } \\
01 \text { ) }\end{array}$ & $94,12 \%$ & $1^{\mathrm{o}}$ \\
\hline Process & $\begin{array}{l}\text { Customer Orientation (CSF- } \\
05 \text { ) }\end{array}$ & $92,65 \%$ & $2^{\circ}$ \\
\hline Management & $\begin{array}{l}\text { Alignment between strategy } \\
\text { and processes (CSF-02) }\end{array}$ & $91,91 \%$ & $3^{\circ}$ \\
\hline Human & $\begin{array}{l}\text { Involvement of people } \\
\text { (CSF-14) }\end{array}$ & $89,71 \%$ & $4^{\circ}$ \\
\hline Process & $\begin{array}{l}\text { Performance measurement } \\
\text { processes - Metrics (CSF- } \\
04 \text { ) }\end{array}$ & $86,03 \%$ & $5^{\circ}$ \\
\hline Human & Communication (CSF-15) & $86,03 \%$ & $6^{\circ}$ \\
\hline Process & $\begin{array}{l}\text { Perception of the value and } \\
\text { benefits of management for } \\
\text { business processes (CSF-08) }\end{array}$ & $83,82 \%$ & $7^{\circ}$ \\
\hline Management & $\begin{array}{l}\text { Change Management (CSF- } \\
\text { 03) }\end{array}$ & $80,15 \%$ & $8^{\circ}$ \\
\hline Process & $\begin{array}{lr}\text { Structured and appropriate } \\
\text { methodology } & \text { for } \\
\text { implementing } & \text { BPM } \\
\text { initiatives (CSF-06) } & \\
\end{array}$ & $78,68 \%$ & $9^{\circ}$ \\
\hline Human & $\begin{array}{l}\text { Organizational Culture } \\
\text { (CSF-13) }\end{array}$ & $78,68 \%$ & $10^{\circ}$ \\
\hline Process & $\begin{array}{l}\text { Sustainable performance of } \\
\text { processes (maintenance and } \\
\text { continuity of process } \\
\text { management in the } \\
\text { organization) (CSF-07) }\end{array}$ & $77,21 \%$ & $11^{\circ}$ \\
\hline Human & $\begin{array}{l}\text { Training and Qualification } \\
\text { of those involved in the } \\
\text { processes and BPM practice } \\
\text { (CSF-12) }\end{array}$ & $76,47 \%$ & $12^{\circ}$ \\
\hline Technology & $\begin{array}{l}\text { Alignment between IT and } \\
\text { processes (CSF-09) }\end{array}$ & $75 \%$ & $13^{\circ}$ \\
\hline Human & $\begin{array}{l}\text { Empowerment in the } \\
\text { execution of business } \\
\text { processes (CSF-16) }\end{array}$ & $63,97 \%$ & $14^{\circ}$ \\
\hline Tecnologia & $\begin{array}{l}\text { Process automation (CSF- } \\
10)\end{array}$ & $47,79 \%$ & $15^{\circ}$ \\
\hline Tecnologia & $\begin{array}{l}\text { Technology tool only } \\
\text { information to process } \\
\text { modeling (CSF-11) }\end{array}$ & $34,56 \%$ & $16^{\circ}$ \\
\hline
\end{tabular}

\section{Conclusion}

The "support and commitment of senior management" has the highest level on the positive influence.
The factor "single information technology tool for process modeling" was the most cited by experts as an aspect that does not influence the success of BPM initiatives, corresponding to $10.30 \%$ of the total of 136 respondents research result. Besides this, other CSF also appeared in the list of aspects that do not influence the success of BPM initiatives, namely: Process Automation (2.94\%); Alignment between IT and processes $(1.47 \%)$; Empowerment in the execution of business processes $(1.47 \%)$; Change Management $(0.74 \%)$; Sustainable performance of processes (maintenance and continuity of process management in the organization) $(0.74 \%)$; Value perception and benefits management for business processes $(0.74 \%)$; Training and Qualification of those involved in the processes and BPM practice $(0.74 \%)$.

Some CSF were evaluated as having a negative influence on the level of success of BPM, namely: Process Automation $(0.74 \%)$; Only information technology tool for process modeling $(0.74 \%)$; Empowerment in the execution of business processes (1.48\%); Training and Qualification of those involved in the processes and BPM practice $(0.74 \%)$; Organizational culture $(0.74 \%)$. Thus, it can be inferred that some experts who evaluated these CSF negative influence on level considered these aspects as barriers and facilitators not in any experience they had in initiatives / BPM projects.

Most (98.44\% ) of the answers of experts were assigned to the level of positive influence. In contrast, very tiny amount of responses were to negative influence level $(0.28 \%)$ and only $(0.09 \%)$ choose "does not apply or I do not wish to answer". Note that only two CSF appeared on the scale "not apply or I do not wish to answer" with a $0.74 \%$ rate each, as follows: Alignment between IT and processes; and, Organizational Culture. Considering the low percentage of the above CSF responses, it appears that most of the experts had no doubts about the matters covered in the questionnaire.

The dimension "Management" leads the ranking of the highest rate of responses from experts, then appears the dimension "Process" with a very small difference of only $0.05 \%$ over the first place. Thirdly, the "Human" dimension $(98.82 \%)$ and finally Technology dimension with an average of $94.36 \%$. It is noteworthy that despite being a BPM practice oriented to business processes, the dimension "Management" stands out first, since this practice is directly aligned to the management of organizations, not being a parallel approach to business management and not just a specific project information technology.

The "Top Ten" CSF that most influence on the success of BPM initiatives/projects, under the perception of the BPM experts surveyed (all of them have CBPP certification) and regarding the sum of the options "positive influence - very high" and "positive influence - high", are listed as follows:

- 1st: Support and Senior Management's commitment (CSF-01);

- 2nd : Customer Orientation (CSF-05);

- 3rd : Alignment between strategy and processes (CSF$02)$;

- 4th: Involvement of people (CSF-14); 
- 5th: Performance measurement processes - Metrics (CSF-04);

- $\quad$ 6th: Communication (CSF-15);

- 7th: Value Perception and benefits of management for business processes (CSF-08);

- 8th: Change Management (CSF-03);

- 9th: Structured Methodology and suitable for the implementation of BPM initiatives (CSF-06);

- 10th: Organizational Culture (CSF-13).

Among the seven (7) critical success factors most cited in the literature review, six (6) were highlighted in the survey as those that most influence the success initiatives of BPM, with the exception of the CSF "Capacity Building and Training of those involved in the processes and practice BPM".

We conclude that the CSF listed in the rankings are relevant to shift the possibility of success in BPM initiatives.

\section{References}

[1] A. Alibabaei, M. Aghdasi, B. Zarei, G. Stewart, "The role of culture in business process management initiatives", Australian Journal of Basic and Applied Sciences, 4, 2143-54, 2010.

[2] A.S. AL-Mudimigh "The role and impact of business process management in enterprise systems implementation. Business Process Management Journal. 13, 866-74, 2007.

[3] ABPMP (Association of Business Process Management Professionals. "BPM CBOK: Guide to the Business Process Management Body of Knowledge". v. 3, 2013.

[4] C. Bai, J. Sarkis, "A grey-based DEMATEL model for evaluating business process management critical success factors", International Journal of Production Economics. 146, 281-92, 2013.

[5] W. Bandara, G. Gable, M. Rosemann, "Factors and measures of business process modeling: model building through a multiple case study". European Journal of Information Systems, v. 14, n. 4, p. 347-360, 2005.

[6] B. Buh, A. Kovačič, M.I. Štemberger, "Critical success factors for different stages of business process management adoption - a case study", Economic Research-Ekonomska Istrazivanja, 28(1), pp. 243258, 2015.

[7] I.H.B. Ceribel, S.I.D. De Pádua, R.M. Merlo, "BPM: A case study of critical success factors", 7, 106-17, 2013.

[8] L.A. Da Silva, I.P.M. Damian, S;I.D., De Pádua, "Process management tasks and barriers: Functional to processes approach", Business Process Management Journal. 18, 762-76, 2012.

[9] B.M.E. De Waal, R. Batenburg, "What makes end-user training successful? A mixed method study of a business process management system implementation", International Journal of Knowledge and Learning. 8, 166-83, 2012.

[10] I. Dias, H.G. Costa, "Interfaces between production engineering and the public affairs: evidences from bibliometric analysis", Scientometrics (Print), v. 3, p. 125, 2015.

[11] J.G. De Freitas, H.G. Costa, F.T. Ferraz. Impacts of Lean Six Sigma over organizational sustainability: A survey study. Journal Of Cleaner Production, v. 156, p. 262-275, 2017.

[12] R. Do Carvalhal Monteiro, V .Pereira; H.G. Costa, "A Multicriteria Approach to the Human Development Index Classification" Social Indicators Research, V. O, p. 1-22, 2017.

[13] Gartner Group "Survey of More Than 2,000 CIOs Identifies Cloud Computing as Top Technology Priority for CIOs", 2011. Acesso em 07/11/2012 http://www.gartner.com/it/page.jsp?id=1526414
[14] Gartner Group, "Survey of More Than 2,000 CIOs Identifies Cloud Computing as Top Technology Priority for CIOs", 2013. Acesso em 08/04/2014 http://www.gartner.com/newsroom/id/2304615

[15] R.J. Goeke, Y.L. Antonucci, "Differences in business process management leadership and deployment: Is there a connection to industry affiliation?” Information Resources Management Journal. 26, 43-63, 2013

[16] M. Helfert, "Challenges of business processes management in healthcare: Experience in the Irish healthcare sector". Business Process Management Journal. 15, 937-52, 2009.

[17] R.Y.Y. Hung, "Business Process Management as competitive advantage: A review and empirical study", Total Quality Management and Business Excellence. 17, 21-40, 2006.

[18] K. Mccormack, 1. J. Willems, J. Bergh, D. Deschoolmeester, P Willaert, M.I. Štemberger, R. Škrinjar, P. Trkman, M.B. Ladeira, M.P.V. De Oliveira, V.B. Vuksic, N. Vlahovic, A global investigation of key turning points in business process maturity. Business Process Management Journal. 15, 792-815, 2009. Doi: 10.1108/14637150910987946.

[19] B. Mutschler, M. Reichert, J. Bumiller, "Unleashing the effectiveness of process-oriented information systems: Problem analysis, critical success factors, and implications", IEEE Transactions on Systems Man and Cybernetics Part C-Applications and Reviews. 38, 280-91. Doi: 10.1109/tsmcc.2008.919197, 2008.

[20] M.P. Méxas, O.L.G. Quelhas, H.G. Costa, "Prioritization criteria for enterprise resource planning systems selection for civil construction companies: a multicriteria approach", Canadian Journal of Civil Engineering, 39(8), 855-866. 2012.

[21] L.D.O. Nepomuceno, H.G. Costa, "Analyzing perceptions about the influence of a master course over the professional skills of its alumni: a multicriteria approach". Pesquisa Operacional, 35(1), p. 187-211, 2015.

[22] B. Niehaves, R. Plattfaut, J. Becker, "Business process management capabilities in local governments: A multi-method study", Government Information Quarterly. 30 (3), pp. 217-225, 2013.

[23] V. Pereira, H.G. Costa, "A literature review on lot size with quantity discounts: 1995-2013". Journal of Modelling in Management 10(3): 341-359. 2015

[24] P. Ravesteyn, R. Batenburg, "Surveying the critical success factors of BPM-systems implementation", Business Process Management Journal. 16, 492-507, 2010.

[25] H.A. Reijers, "Implementing BPM systems: The role of process orientation”. Business Process Management Journal. 12, 389-409, 2006.

[26] T. Schmiedel, J. Vom Brocke, J. Recker, "Which cultural values matter to business process management?: Results from a global Delphi study", Business Process Management Journal. 19, 292-317, 2013.

[27] O. F. Sentanin, F. C. A. Santos, Charbel J. C. Jabbour, Business Process Management Journal, Vol. 14 Issue: 4, pp.483496,https://doi.org/10.1108/14637150810888037, 2-8.

[28] R. Škrinjar, P. Trkman, "Increasing process orientation with business process management: Critical practices'”, International Journal of Information Management. 33, 48-60, 2013.

[29] M.I. Štemberger, V. Bosilj-Vukšić, J. Jaklič, "Business process management software selection - Two case studies", Ekonomska Istrazivanja. 22, 84-99, 2009

[30] P. Trkman, "The Critical success factors of business process management", International Journal of Information Management, v. 30, n. 2 , p. $125-134,2010$.

[31] D. Tuček, M. Hájková, Z. Tučková "Utilization Level of Business Process Management in Czech Enterprises - Objectives and Factors", Economics \& Management. v. 16, n. 2, p. 81-98, 2010.

[32] J. Vom Brocke, T. Sinnl, "culture in business process management: A literature review", Business Process Management Journal.17, 357-78, 2011

[33] J. Vom Brocke, S. Zelt; T. Schmiedel, "On the role of context in business process management", International Journal of Information Management, 36(3), pp. 486-495, 2016. 